\title{
ARTICLE
}

\section{Addressing the sexual and reproductive health needs of women who use mental health services $^{\dagger}$}

\author{
Carol Henshaw \& Olivia Protti
}

Carol Henshaw is a consultant in perinatal mental health with Liverpool Women's NHS Foundation Trust. She has previously worked as a consultant general adult psychiatrist in Cheshire and a senior lecturer in perinatal psychiatry at the School of Medicine, Keele University. She has a special interest in perinatal psychiatry, menstrual mood disorders and other aspects of women's mental health. Olivia Protti is a consultant general adult psychiatrist with North East London Mental Health Trust. She has an interest in women's mental health issues and perinatal psychiatry, having worked in obstetrics and gynaecology prior to her psychiatry training.

Correspondence Dr Carol Henshaw, Liverpool Women's NHS Foundation Trust, Crown Street, Liverpool L8 7SS, UK. Email: chenshaw@doctors.org.uk

tFor a commentary on this article see pp. 279-280, this issue.

\begin{abstract}
SUMMARY
Pregnancies in women with serious mental illness are high risk and such women are also less likely to engage in the recommended health screening for women of reproductive age. Hence, reproductive health issues are important aspects of physical healthcare that should be assessed in women accessing mental health services. Pregnancy planning and management are crucial in reducing risk of relapse in women with affective disorders, and psychiatrists should acquaint themselves with the screening programmes and reproductive and sexual health services in their area and encourage their patients' uptake of these. Clinicians should be aware of the reproductive impact of medications and the needs of specific groups of women.
\end{abstract}

\section{DECLARATION OF INTEREST}

Both authors are members of the Royal College of Psychiatrists' Women in Psychiatry Special Interest Group. This article was written as part of their input to the Physical Health of Women with Mental Illness work stream.

Women with serious mental illness tend to have more lifetime sexual partners, rendering them at greater risk of sexually transmitted infection (Dickerson 2004) and more likely to experience coercive sex (Coverdale 1997). They are more likely to have unplanned pregnancies, less likely to receive antenatal care while pregnant and more likely to smoke during pregnancy than women in the general population (Shah 2006). Their pregnancies involve a higher risk of complications such as placental abnormalities and abruption, gestational diabetes, fetal or neonatal death, stillbirth, antepartum haemorrhage, preterm labour and fetal distress, and their infants are more likely to be small for gestational age, of low birth weight and at higher risk of sudden infant death syndrome (Howard 2003; Jablensky 2005; KingHele 2007; Nilsson 2002, 2008; Webb 2005, 2006,
2008). In addition, women with serious mental illness are more likely to be single mothers or to have partners who are unemployed or disabled, to be socially disadvantaged, lacking in social support and to be either very young $(<20$ years) or older (>35 years) mothers (Jablensky 2005). People with psychotic disorders are more likely than those without such disorders to use illicit drugs before pregnancy and to drink and/or use drugs during pregnancy.

Women with mental illness are also less likely to attend breast cancer screening (Carney 2006; Werneke 2006). Reasons given for failing to attend include difficulties getting to appointments, belief that the procedure itself can cause cancer, fear of a positive result, shame and embarrassment, and lack of knowledge about breast cancer and mammography (Khan 2005; Miller 2007).They are also less likely to have had cervical smears or hormone replacement therapy (HRT) than women who do not have a mental disorder (Lindamer 2003).

Women with serious mental illness commonly cite the reason for not using contraception as being that they did not expect to have sexual intercourse when it occurred. Rarely are there delusional beliefs about contraception but often misconceptions about the likelihood of becoming pregnant (Miller 1998).

Despite these alarming statistics, primary and secondary care services are poor at meeting the needs of these women. There is evidence that general practitioners (GPs) are less likely to record smoking or alcohol consumption in pregnant, mentally ill women (McLennan 1999) and that women with psychotic disorders are less likely to have received contraceptive advice (Howard 2003). Mental health workers have estimated that $49 \%$ of their female patients are sexually active and that $22 \%$ use contraception. However, birth control is discussed with the patient in only a third of cases (McLennan 1999). Clinicians were more confident in knowing their patients' sexual activity status 
than whether they were using contraception, and there was no clinician gender bias.

\section{History-taking}

Engaging a woman patient in dialogue regarding women's health should be a routine part of care. When assessing any woman, the taking of the medical history should include gynaecological and obstetric history, including the number of pregnancies and outcome, and whether there has been unprotected intercourse or sexual assault. Ascertain whether there is any personal or family history of psychiatric episodes in relation to pregnancy and childbirth. This is particularly pertinent if the patient is pregnant or planning a pregnancy (National Collaborating Centre for Mental Health 2007).

Contraception and sexual health must be enquired about in all women of reproductive potential and they should be asked whether or not they have had routine cervical and breast cancer screening. This is less likely in those not accessing primary care or those who are highly mobile (frequently change address).

The most common cause of amenorrhoea in any woman is pregnancy, but women with menstrual irregularities or absent periods due to low weight or drug-induced hyperprolactinaemia are at increased risk of osteoporosis and sexual dysfunction (O'Keane 2008; Smith 2008).

Women who are overweight, have irregular or heavy periods, acne and/or hirsutism may be suffering from polycystic ovarian syndrome. This can cause infertility and confers long-term increased risk of endometrial cancer, diabetes, cardiovascular disease and hypertension, so early recognition and treatment are important. Valproate should not be prescribed to women under the age of 18 because it increases the risk of the syndrome and because this group are at particular risk of unplanned pregnancy (valproate is teratogenic and increases the risk of neural tube defects).

Lifestyle factors such as drug and alcohol use, ${ }^{\ddagger}$ smoking, exercise and diet can influence pregnancy outcome and are potentially modifiable, so should also be assessed.

\section{Admission to hospital or home treatment}

On admission to hospital or initial engagement in home treatment, ascertain the date of the last menstrual period and, if the patient has capacity, ask permission to undertake a pregnancy test before administering medication. If the woman lacks capacity, then it is in her best interests to perform a pregnancy test. Enquire sensitively about unplanned or non-consensual sexual intercourse.
Consider referral to a sexual health clinic or to a specialist clinic for sexual assault victims if this history is positive. Ensure that there is access to emergency contraception: it is highly effective up to 5 days after intercourse (levonorgestrel, 'the morning after pill', is $98.5 \%$ effective if used within $72 \mathrm{~h}$ and insertion of an intrauterine device is almost $100 \%$ effective within 5 days).

Mixed-gender psychiatric wards are being phased out (Department of Health 2000), but in those that remain there is increased possibility of unprotected sex and assault. Unwanted violence is common and women are particularly vulnerable to sexual assault (Thomas 1995). Whether women are admitted to hospital or being cared for in the community, every attempt should be made to protect them at a time when they may be disinhibited or particularly vulnerable. Leaflets and information about contraception and sexual health should be available for women on the ward, written in the languages most common in the locality.

Women's reproductive health needs should be included in the discharge summary to the GP and advice on pregnancy planning can be part of predischarge planning.

The long-term reliable contraceptive options with high success rates that are suited to women with severe mental illness or highly mobile chaotic lifestyles are listed in Table 1. A review of the current evidence-based choices in contraception is available in Amy \& Tripathi (2009).

\section{Current UK screening programmes}

\section{Cervical screening}

All women in the UK aged between 25 and 64 are offered a free cervical screening test every 3-5 years. Those aged 25-49 are screened every 3 years and those 50-64 every 5 years. Women 65 and older are not routinely screened unless they have not had a test since the age of 50, or have had previous abnormal test results.

A considerable number of women with mental disorders have a history of abuse. Those with a history of childhood sexual abuse are less likely to attend for cervical smears (Farley 2002). Hence, they may require support and encouragement

\section{${ }^{\ddagger}$ Readers may also be interested in Day E, George S (2005) Management of drug misuse in pregnancy. Advances in Psychiatric Treatment 11: 253-61. Ed.}

\section{TABLE 1 Reliable long-acting contraceptive methods}

\begin{tabular}{|lcc|}
\hline Contraceptive method & Success rate, \% & Duration of action \\
\hline $\begin{array}{l}\text { Injectables (e.g. depot } \\
\text { medroxyprogesterone acetate) }\end{array}$ & $>99$ & 3-monthly injection \\
\hline Progestogen-only implant & $>99$ & 3 years \\
\hline Intrauterine progestogen-only system & $>99$ & 5 years \\
\hline Intrauterine device & 99 & $3-10$ years \\
\hline
\end{tabular}


to attend, with the technician undertaking the screening having been forewarned. A woman with capacity may refuse to undergo screening and her reasons for doing so should be explored and addressed if possible. If she continues to refuse, this should be recorded.

Keeping Healthy 'Down Below' (Hollins 2000a) is a picture book aimed at women with intellectual disability and it can be used before the procedure to allay anxiety.

\section{Breast cancer screening}

Women over the age of 50 are offered a mammogram every 3 years until they are 70 . A woman can be expected to receive her first invitation to attend a GP screening unit between her 50th and 53rd birthdays. Women with special needs (e.g. with an intellectual disability) or their carers can contact the screening unit and arrange for more time for the examination and for a supporter to attend. Women with mental illness are more likely to attend mammography screening if they have a good relationship with the primary care team, who persist in encouraging them and rescheduling missed appointments (Miller 2007).

Although there is no evidence that formal selfexamination techniques reduce deaths from breast cancer, women should be encouraged to learn what is normal for them, check their breasts regularly and be aware of the warning signs. A helpful leaflet (in 19 languages in addition to English) can be downloaded from www.cancerscreening.nhs.uk/ breastscreen/publications/be-breast-aware.html.

B0X 1 The Fraser guidelines

1 The young person understands the advice being given

2 The young person cannot be convinced to involve parents/carers or allow the medical practitioner to do so on their behalf

3 It is likely that the young person will begin or continue having intercourse with or without treatment/contraception

4 Unless they receive treatment/ contraception, their physical or mental health (or both) is likely to suffer

5 The young person's best interests require contraceptive advice, treatment or supplies to be given without parental consent

Although these criteria specifically refer to contraception, the principles are deemed to apply to other treatments, including termination of pregnancy.

If a person under the age of 18 refuses to consent to treatment, it is possible in some cases for their parents or the courts to overrule their decision. However, this right can only be exercised on the basis that the welfare of the young person is paramount. In this context, welfare does not simply mean their physical health. The psychological effect of having the decision overruled would have to be taken into account and would normally only be an option when the young person was thought likely to suffer 'grave and irreversible mental or physical harm'. Usually when a parent wants to overrule a young person's decision to refuse treatment, health professionals will apply to the courts for a final decision.
The picture book Looking After My Breasts (Hollins $2000 b)$ describes for women with intellectual disability how to check their breasts and what happens during breast screening.

\section{Contraception and safe sex}

Contraception and the risks of pregnancy (including relapse, risk to the fetus and risks associated with stopping or changing medication) must be discussed with all women of childbearing potential who have an existing mental disorder and/or who are taking psychotropic medication. Contraceptive advice can be obtained via the woman's GP practice or the local family planning clinic. Women having unprotected intercourse are also at risk of sexually transmitted infections, including blood-borne viruses. Referral to a sexual health clinic should be offered to any woman suspected of having a sexually transmitted infection or who is concerned about her hepatitis B, C or HIV status.

\section{Young people, contraception and termination of pregnancy}

Those working with young people must be aware of the legal situation relating to under-18-year-olds. In England, Wales and Northern Ireland, the 18th birthday is deemed to be the borderline between childhood and adulthood. The Family Law Reform Act 1969 gave the right to consent to treatment to anyone aged 16-18.

For children under the age of 16, a parent's right to consent to treatment on behalf of their child ends when the child has sufficient intelligence and understanding to consent to the treatment themselves (i.e. when the child becomes 'Gillick competent'). It is for the doctor to decide whether a child has reached this level. The guidelines apply not only to the prescription of contraceptives, but also to all aspects of the care of under-16-yearolds. Narrower criteria, the Fraser guidelines, relate specifically to contraception (Box 1).

In Scotland, the 16th birthday draws the line between childhood and adulthood. Under the Age of Legal Capacity (Scotland) Act 1991, in certain circumstances, a person younger than 16 will be deemed to have the capacity to consent to any surgical, medical or dental treatment or procedure with the proviso that they are capable of understanding the nature and consequences of the proposed treatment or procedure.

\section{Pregnancy planning}

Ask all women of reproductive potential whether they are planning a pregnancy. If so, it is important to counsel them about the risks posed by pregnancy 
and childbirth to their condition (e.g. the high risk of recurrence of bipolar disorder postnatally) and to consider whether it is safe to conceive on their current medication or whether an alternative needs to be considered. Many women will want to know the genetic risk of their children inheriting their mental health condition.

The risks of relapse and recurrence if stopping treatment before, during or after pregnancy must be established for each individual and clearly communicated.

Pregnancy spacing may also be relevant, particularly following an episode of perinatal illness, as a woman with serious mental illness may cope less well with successive pregnancies close together than a few years apart.

Pre-pregnancy advice is available from family planning clinics, for example on folate, rubella, sexually transmitted infection testing, drugs, alcohol, exercise, diet and stress reduction.

\section{Managing pregnancy}

Women who have no or few antenatal care visits are at higher risk of having infants of low birth weight and of fetal death (Raatikainen 2007). If a woman with mental disorder is pregnant, check whether or not she is booked for antenatal care. If not, she requires referring, and if already booked for antenatal care, maternity services should be informed if she is admitted to hospital and a midwifery assessment requested. A woman who is in the very early stages of pregnancy will require an ultrasound scan to assess viability and exclude ectopic pregnancy.

Before any treatment decisions are made, the absolute and relative risks of treating the mental disorder must be discussed with the woman. It is best to use frequencies (e.g. one in ten) rather than percentages. It is important to explain that the risk of fetal malformation in the general population without a mental disorder is 3 in 100 and if possible use visual and verbal formats to convey the individual risk to the woman concerned. Audio-taping the conversation and providing written material are useful ways of ensuring it can be referred to later.

All women with serious mental illness who are pregnant and admitted to hospital should be referred to the fetal monitoring unit for fetal growth scans and Doppler ultrasound assessment of uterine artery and placental blood flow.

On discharge or overnight leave from a mother and baby unit or admission elsewhere, postpartum women should be offered adequate contraception and warned that ovulation can return by day 28 after delivery if they are not breastfeeding. Future pregnancy planning can be discussed during the preparations for discharge and should be included in management plans and communicated to primary care. The health visitor should be invited to attend discharge-planning meetings. Attendance at the 6 -week postpartum check should be facilitated.

\section{Fertility problems}

The Human Fertilisation and Embryology Act 1990 (Section 13(5)) states that a woman should not be offered fertility treatment unless account is taken of the welfare of the child that might result from these procedures. The Human Fertility and Embryology Authority (HFEA), which governs fertility treatment in the UK, require all fertility clinics to perform an assessment of the "welfare of the child' prior to offering in vitro fertilisation and other assisted reproductive techniques. Before offering treatment, the clinician is required to consider the needs of the child or any existing children and the potential risks of serious harm from parental mental or physical illness.

\section{Menopause}

The average age at menopause in the UK is 50 . The period from 47 to 52 is referred to as the perimenopause. Perimenopausal symptoms should be screened for, as these can have an impact on mental well-being and impair quality of life (Friedman 2005). If problematic, symptoms may require treatment. The most common are hot flushes and/ or cold sweats, menstrual cycle changes, weight gain, sleep problems and altered libido or sexual responsiveness. Some women experience depressive symptoms which may remit when other menopausal symptoms remit, or if they are persistent, may need antidepressant therapy. A comprehensive review by Gyllstrom et al (2007) discusses the relationship between the perimenopause and depression.

The second peak incidence of schizophrenia in women occurs post-menopause. There is one small study suggesting that HRT is associated with fewer negative symptoms in women with schizophrenia (Lindamer 2001).

Post-menopausal bleeding is associated with malignancy and requires urgent referral to gynaecology for investigation. Clinicians working with older women with intellectual disability or dementia need to be particularly aware that their patients may not understand the significance of post-menopausal bleeding and may not report it. Similarly, they may not report breast changes or lumps. Therefore careful attention must be paid when examining in-patients, and out-patients' attendance at regular primary care health checks should be facilitated. 
MCO answers

1 c 2 e 3 a 4 b $5 d$

\section{Medication and side-effects}

When enquiring about side-effects remember to ask about sexual side-effects and impact on the menstrual cycle. Demonstrable bone density loss occurs after 6 months of amenorrhoea, so ask about regular periods and check for hyperprolactinaemia.

A particular issues relating to reproductive health is failure to consider the impact of switching from a high prolactin-inducing medication to a lower one (e.g. clozapine, quetiapine). A woman with previous amenorrhoea may become able to conceive, so careful consideration of contraceptive needs is essential before switching.

\section{Drug interactions with oral contraceptives}

The contraceptive effect of oestrogens and progestogens can be reduced by St John's Wort, so concomitant use is best avoided. Oestrogens and progestogens reduce plasma concentrations of lamotrigine and increase the metabolism of carbamazepine. Conversely, carbamazepine increases the metabolism of oestrogens and progestogens, leading to a possible reduction in contraceptive effect.

\section{Drugs, pregnancy and breastfeeding}

Ensure that any potential teratogenic effect of drugs prescribed is discussed with all patients of reproductive potential. For example, if prescribing valproate to a woman of childbearing potential is unavoidable, she must be advised about reliable contraception and prescribed $5 \mathrm{mg} /$ day folic acid. The combination of drugs should be avoided if possible as this raises the risk of fetal anomaly. Women caring for small children who are waking at night should not be prescribed sedative drugs.

Consideration of other effects on a fetus is essential, including the possibility of neonatal withdrawal syndromes. Whether or not breastfeeding is possible on the woman's current medication or whether a change is required should also be addressed in pregnancy.

Management plans regarding medication and care during pregnancy and the postpartum period must be communicated to maternity and primary care and a copy placed in the woman's handheld record. The National Collaborating Centre for Mental Health (2007) provides advice regarding specific drugs and groups of drugs in relation to pregnancy.

\section{Cultural needs}

It is important to take into account the cultural views of the woman. The effects of amenorrhoea or menstrual irregularities may have an impact on religious practice. For example, Orthodox Jewish women attend ritual immersion following menstruation. Some women may not accept certain contraceptive methods for religious reasons (e.g. some Catholic women).

\section{Sexual health needs of lesbian and bisexual women}

Lesbian and bisexual women may also plan pregnancies and may have difficulties accessing generic services, perceiving barriers and not disclosing their sexuality to healthcare providers. They are less likely to attend routine cervical and breast screening tests, and more likely to be overweight and to consume more alcohol than heterosexual women. If a lesbian couple are considering a pregnancy via donor insemination, a list of clinics which provide this is available from the HFEA (www.hfea.gov.uk) and they should be referred. There are three sexual health clinics in the UK specifically for lesbian and bisexual women (Box 2). For more information see Fish (2007).

\section{Domestic violence}

Women with serious mental illness experience high levels of violence and sexual assault (Coverdale 2000; Mueser 2004) in addition to childhood sexual abuse. The prevalence of intimate partner violence among women with serious mental illness is high (Friedman 2007). The most recent Confidential Enquiry into Maternal Deaths report highlights certain vulnerability factors associated with maternal death in pregnancy and the puerperium. Of all maternal deaths from any cause, $14 \%$ had disclosed a history of domestic violence. A large proportion of these women were less likely to access adequate antenatal care (Lewis 2007).

About one in four women are victims of domestic violence in their lifetime regardless of background or social circumstances. Abuse frequently starts in pregnancy and is a cause of stillbirth and miscarriage. In England and Wales, on average two women each week are killed by their partner or ex-partner (Povey 2005). It is often difficult for

BOX 2 Sexual health clinics for lesbian and bisexual women in the UK

Orange Clinic, West London Centre for Sexual Health Charing Cross Hospital, Fulham Palace Road, London W6 8RF

Sandyford Initiative (www.sandyford.org), 2-6 Sandyford Place, Glasgow G3 7NB

Vita Clinic, Harrison Department, Churchill Hospital, Headington, Oxford OX3 7LJ 
clinicians to ask about intimate partner violence and staff need adequate training to be able to respond appropriately and in a non-judgemental way. The clinician may be the first person to whom disclosure is made. Staff need to feel confident to provide effective advice and support both in a crisis or in routine clinical work. Practical advice and the number of local refuges, helpline numbers and useful websites can be offered as further sources of help, so ensure that you have these to hand (Box 3). Useful practical advice for clinicians is available on the Greater London Domestic Violence Project website (www.gldvp.org.uk). If a woman is identified to be at significant risk of domestic violence then consideration will need to be given to instituting 'vulnerable adult' proceedings according to local policy and to establishing multi-agency care plans to tackle the risks.

The Royal College of Psychiatrists (2002) and the Department of Health (2005) provide further information and guidance.

\section{Multi-agency risk assessment conferencing}

Multi-agency risk assessment conferencing (MARAC) is being rolled out across the UK. The key element is the risk assessment, which will be carried out by police officers attending incidents of domestic abuse. The risk assessment has three main objectives:

- to gather detailed and relevant information from victims, which can be shared with other agencies

- to identify those who will need more intensive support

- to make agencies aware of the most dangerous offenders.

Information gathered during these risk assessments will then be shared with relevant agencies to promote the safety of abused women and their children. Psychiatrists may be involved if their patients are victims or offenders.

\section{Care pathways in the National Health Service}

Family planning services, emergency contraception and sexually acquired infection/blood-borne virus screens are available from family planning clinics, GPs and sexual health clinics. Emergency contraception is also available from pharmacists, and some substance misuse clinics provide sexually acquired infection/blood-borne virus screens.

Termination of pregnancy services are available from family planning clinics and GPs, as well as the Pregnancy Advisory Service and Marie Stopes clinics (available in some areas). Some women
BOX 3 National helplines and useful websites
Helplines

Women's Aid (www.womensaid.org.uk) and

Refuge (www.refuge.org.uk) both provide advice and assistance about domestic violence and collaboratively run a 24-hour helpline (0800 2000 247)

British Pregnancy Advisory Service (www. bpas.org); tel: 08457304030

Marie Stopes International (www. mariestopes.org.uk); 24-hour helpline: 0845 3008090

Family planning helpline (0845 122 8690) has information on sexual and contraceptive health and where to access local services

Websites

NHS Breast Cancer Screening Programme (www.cancerscreening.nhs.uk/breastscreen/ index.html) has a number of leaflets, including a picture version for women with intellectual disabilities

NHS Breast Cancer Screening Programme (www.cancerscreening.nhs.uk/cervical/ index.html) also has information on the screening programme and a range of leaflets Family Planning Association (www.fpa.org. contraception and sexual health

Further reading (wider aspects of reproductive health)

Anderson BA (2005) Reproductive Health Women and Men's Shared Responsibility. Bartlett \& Jones.

Cook RJ, Dickens BM, Fathalla MF (2003) Reproductive Health and Human Rights: Integrating Medicine, Ethics and Law. Oxford University Press. uk) gives useful information on services,

may prefer more anonymity than is available in local services.

Early-pregnancy clinics are available in most gynaecology departments and assess early pregnancy disorders such as threatened miscarriage or ectopic pregnancy.

Fetal medicine services are available in obstetric departments and offer screening of highrisk pregnancies, assessment and occasionally treatment of fetal abnormalities.

You should ensure that you have at your reach the contact details of services in your area such as those listed in Box 3.

\section{References}

Amy J-J, Tripathi V (2009) Contraception for women: an evidence-based overview. BMJ 339: b2895.

Carney CP, Jones LE (2006) The influence of type and severity of mental illness on receipt of screening. Journal of General Internal Medicine 21: 1097-104.

Coverdale JH, Turbott SH, Roberts H (1997) Family planning needs and STD risk behaviours of female psychiatric out-patients. British Journal of Psychiatry 171: 69-72.

Coverdale JH, Turbott SH (2000) Sexual and physical abuse of chronically ill psychiatric outpatients compared with a matched sample of medical outpatients. Journal of Nervous and Mental Disease 188: 440-5.

Department of Health (2000) Safety, Privacy and Dignity in Mental Health Units. Guidance on Mixed Sex Accommodation for Mental Health Services. TSO (The Stationery Office)

Department of Health (2005) Responding to Domestic Abuse: A Handbook for Health Professionals. TSO (The Stationery Office).

Dickerson FB, Brown CH, Kreyenbuhl J, et al (2004) Sexual and reproductive behaviors among persons with mental illness. Psychiatric Services 55: 1299-301.

Farley M, Golding JM, Minkoff JR (2002) Is a history of trauma associated with a reduced likelihood of cervical cancer screening? Journal of Family Practice 51: 827-31. 
*Fish J (2007) Briefing 5: Lesbian Health. Department of Health.

Friedman SH, Sajatovic M, Schuermeyer IN, et al (2005) Menopauserelated quality of life in chronically mentally ill women. International Journal of Psychiatry in Medicine 35: 259-71.

Friedman SH, Loue S (2007) Incidence and prevalence of intimate partner violence by and against women with severe mental illness. Journal of Women's Health 16: 471-80.

*Gyllstrom ME, Schreiner PJ, Harlow BL (2007) Perimenopause and depression: strength of association, causal mechanisms and treatment recommendations. Best Practice and Research Clinical Obstetrics and Gynaecology 21: 275-92.

Hollins S, Downer W (2000a) Keeping Healthy 'Down Below'. Gaskell St George's Hospital Medical School.

Hollins S, Perez W (2000) Looking After My Breasts. Gaskell/St George's Hospital Medical School.

Howard LM, Goss C, Leese M, et al (2003) Medical outcome of pregnancy in women with psychotic disorders and their infants in the first year after birth. British Journal of Psychiatry 182: 63-7.

Jablensky AV, Morgan V, Zubrick SR, et al (2005) Pregnancy, delivery, and neonatal complications in a population cohort of women with schizophrenia and major affective disorders. American Journal of Psychiatry 162: 79-91.

Kahn LS, Fox CH, Krause-Kelly J, et al (2005) Identifying barriers and facilitating factors to improve screening mammography rates in women diagnosed with mental illness and substance use disorders. Women and Health 42: 111-26.

King-Hele SA, Abel K, Webb RT, et al (2007) Risk of sudden infant death syndrome with parental mental illness. Archives of General Psychiatry 64: $1323-30$

Lewis G (ed) (2007) Saving Mothers' Lives: Reviewing Maternal Deaths to Make Motherhood Safer - 2003-2005. The Seventh Report on Confidential Enquiries into Maternal Deaths in the United Kingdom. Confidential Enquiry into Maternal and Child Health.

Lindamer LA, Buse DC, Lohr JB, et al (2001) Hormone replacement therapy in postmenopausal women with schizophrenia: positive effect on negative symptoms? Biological Psychiatry 49: 47-51.

Lindamer LA, Buse DC, Auslander L, et al (2003) A comparison of gynecological variables and service use among older women with and without schizophrenia. Psychiatric Services 54: 902-4

McLennan JD, Ganguli R (1999) Family planning and parenthood needs of women with severe mental illness: clinicians' perspective. Community Mental Health Journa/ 35: 369-80.

Miller LJ, Finnerty M (1998) Family planning knowledge, attitudes and practices in women with schizophrenic spectrum disorders. Journal of Psychosomatic Obstetrics and Gynecology 19: 210-7.

Miller E, Lasser KE, Becker AE (2007) Breast and cervical cancer screening for women with mental illness: patient and provider perspectives on improving linkages between primary care and mental health. Archives of Women's Mental Health 10: 189-97.

Mueser KT, Salyers MP, Rosenberg SD, et al (2004) Interpersonal trauma and posttraumatic stress disorder in patients with severe mental illness: demographic, clinical, and health correlates. Schizophrenia Bulletin 30 : 45-57.

*National Collaborating Centre for Mental Health (2007) Antenatal and Postnatal Mental Health: Clinical Management and Service Guidance. National Institute of Clinical Excellence.

Nilsson E, Lichtenstein P, Cnattingius S, et al (2002) Women with schizophrenia: pregnancy outcome and infant death among their offspring. Schizophrenia Research 58: 221-9.

Nilsson E, Hultman CM, Cnattingus S, et al (2008) Schizophrenia and offspring's risk for adverse pregnancy outcomes and infant death. British Journal of Psychiatry 193: 311-5.

O'Keane V (2008) Antipsychotic-induced hyperprolactinaemia, hypogonadism and osteoporosis in the treatment of schizophrenia. Journal of Psychopharmacology 22 (2 suppl): 70-5.

Povey D (ed) (2005) Crime in England and Wales 2003/2004: Supplementary Volume 1: Homicide and Gun Crime. Home Office Statistical Bulletin No. 02/05. Home Office.

Raatikainen K, Heiskanen N, Heinonen S (2007) Under-attending free antenatal care is associated with adverse pregnancy outcomes. BMC Public Health 7: 268.

Royal College of Psychiatrists (2002) Domestic Violence (Council Report CR102). Royal College of Psychiatrists.

Shah N, Howard L (2006) Screening for smoking and substance misuse in pregnant women with mental illness. Psychiatric Bulletin 30: 294-7.

Smith SM (2008) The impact of hyperprolactinaemia on sexual function in patients with psychosis. Journal of Psychopharmacology 22 (2 suppl): $63-9$

Thomas C, Bartlett AEA, Mezey GC (1995) The extent and effects of violence among psychiatric in-patients. Psychiatric Bulletin 19: 600-4.

Webb R, Abel K, Pickles A, et al (2005) Mortality in offspring of parents with psychotic disorders: a critical review and meta-analysis. American Journal of Psychiatry 162: 1045-56.

Webb RT, Abel KM, Pickles A, et al (2006) Mortality risk among offspring of psychiatric inpatients: a population-based follow-up to early adulthood. American Journal of Psychiatry 163: 2170-7.

Webb RT, Pickles AR, King-Hele SA, et al (2008) Parental mental illness and fatal birth defects in a national birth cohort. Psychological Medicine 38: 1495-1503.

Werneke U, Horn 0, Maryon-Davis A, et al (2006) Uptake of screening for breast cancer in patients with mental health problems. Journal of Epidemiology and Community Health 60: 600-5.

* Key publications.

MCOs
Select the single best option for each question stem
1 The following are increased risks during
pregnancy in women with serious mental
illness:
a postpartum haemorrhage
b macrosomia
c placental abruption
d anaemia
e twin pregnancies.

2 The following are features suggestive of polycystic ovarian syndrome:

a weight loss

$\begin{array}{ll}\text { b hypothyroidism } & \text { b St John's Wort } \\ \text { c hair loss } & \text { c sertraline } \\ \text { d ankle oedema } & \text { d gabapentin } \\ \text { e menorrhagia. } & \text { e quetiapine. }\end{array}$

\section{Cervical cancer screening:}

a is offered every 3 years to women aged 25-49

b is offered every 3 years to women aged $18-24$

c is offered every 5 years to women over 65

$\mathrm{d}$ should be avoided in cases of sexual abuse.

\section{The contraceptive effect of oestrogens and progestogens can be reduced by: a phenytoin}

\section{The following are highly effective} contraceptive methods suitable for women with severe mental illness:

a progestogen-only pill

b diaphragm

c condom

d intrauterine progestogen system

e combined oral contraceptive pill. 